\title{
Systemic Infection of Nicotiana benthamiana with Potato virus $X$ Nanoparticles Presenting a Fluorescent iLOV Polypeptide Fused Directly to the Coat Protein
}

\author{
Juliane Röder (D), Christina Dickmeis, Rainer Fischer, and Ulrich Commandeur $(\mathbb{D}$ \\ Institute for Molecular Biotechnology, RWTH Aachen University, Worringerweg 1, 52072 Aachen, Germany \\ Correspondence should be addressed to Ulrich Commandeur; commandeur@molbiotech.rwth-aachen.de
}

Received 28 June 2017; Accepted 25 December 2017; Published 13 February 2018

Academic Editor: Michael Kalafatis

Copyright (C) 2018 Juliane Röder et al. This is an open access article distributed under the Creative Commons Attribution License, which permits unrestricted use, distribution, and reproduction in any medium, provided the original work is properly cited.

\begin{abstract}
Plant virus-based nanoparticles can be produced in plants on a large scale and are easily modified to introduce new functions, making them suitable for applications such as vaccination and drug delivery, tissue engineering, and in vivo imaging. The latter is often achieved using green fluorescent protein and its derivatives, but the monovalent fluorescent protein iLOV is smaller and more robust. Here, we fused the iLOV polypeptide to the N-terminus of the Potato virus $X$ (PVX) coat protein, directly or via the Foot-and-mouth disease virus 2A sequence, for expression in Nicotiana benthamiana. Direct fusion of the iLOV polypeptide did not prevent the assembly or systemic spread of the virus and we verified the presence of fusion proteins and iLOV hybrid virus particles in leaf extracts. Compared to wild-type PVX virions, the PVX particles displaying the iLOV peptide showed an atypical, intertwined morphology. Our results confirm that a direct fusion of the iLOV fluorescent protein to filamentous PVX nanoparticles offers a promising tool for imaging applications.
\end{abstract}

\section{Introduction}

The functionalization of plant virus-based nanoparticles is an emerging field, facilitated by the well-characterized genomic sequence and modular organization of many different plant viruses [1-3]. Plant viruses come in various shapes and sizes with different surface properties, allowing researchers to pick the most suitable virus for a given application. The structures of many plant viruses are known to atomic or nearatomic resolution [4-7]. The advantages of plant virusbased nanoparticles include their ability to self-assemble with precise symmetry and polyvalency, their monodispersity and stability under a range of conditions, their inherent safety (biocompatibility and noninfectivity in mammals), and the rapid, simple and scalable production that can be achieved by molecular farming in plants [8]. None of these properties can be matched by synthetic nanoparticles.

Potato virus $X$ (PVX) is the type member of the genus Potexvirus (family Alphaflexiviridae) and is often used as a vector for heterologous gene expression in plants [9-18]. The complete $6.4 \mathrm{~kb}$ genomic RNA sequences of several PVX strains are known [19-21]. The plus-strand RNA genome has a $5^{\prime}$-methylguanosine cap and is polyadenylated at the $3^{\prime}$ terminus [22, 23]. Each PVX particle comprises $\sim 1270$ coat protein $(\mathrm{CP})$ subunits helically arranged to form filamentous, flexible virions encapsidating the viral genomic RNA. The C-terminus of each CP subunit is located within the PVX particle whereas the $\mathrm{N}$-terminus is exposed on the surface, providing an ideal site for the presentation of peptides and proteins [4, 24-28].

Genetic modification or chemical conjugation can be used to tailor the surface properties of plant viruses allowing them to be engineered, for example, as drug delivery vehicles, tissue scaffolds, and electronic devices [1, 8, 29-32]. Furthermore, fluorescence-labeled virus nanoparticles can be used for biomedical imaging [33-39]. Such labeling is usually achieved by the conjugation of chemical dyes to functional groups on the virus surface after particle assembly. Several studies have shown that PVX particles carrying molecular contrast agents such as Alexa Fluor647 can efficiently penetrate solid tumors and accumulate inside [40-42]. However, chemical conjugation results in a limited number of tagged 
TABLE 1: Oligonucleotides used for PCR and cDNA synthesis.

\begin{tabular}{lc}
\hline Primer name & Nucleotide sequence $\left(5^{\prime} \rightarrow 3^{\prime}\right)$ \\
\hline NheI-iLOV & AAAGCTAGCATGGCAAGCATAGAGAAGAA \\
iLOV-BspEI & TTTTCCGGATACATGATCACTTCCATCGA \\
iLOV-Stop-Not & TTTGCGGCCGCTTATACATGATCACTTCCATCGAGC \\
M13 rev & ACACAGGAAACAGCTATGAC \\
M13 fw & GTTGTAAAACGACGGCCAGT \\
TGB-fw & AAGGGCCATTGCCGATCTCAAGC \\
CX1 & TTGAAGAAGTCGAATGCAGC \\
CX3i & GAAGTGCTAATGACTGCTAT \\
CX4 & CGGGCTGTACTAAAGAAATC \\
CX4i & GATTTCTTTAGTACAGCCCG \\
CX8 & AGCTCTGCTGATGCCGTTGG \\
\hline
\end{tabular}

$\mathrm{CP}$ subunits, whereas the genetic fusion of a fluorescent protein to the CP allows denser labeling [35]. The latter strategy can be challenging because the size and biochemical properties of the fusion protein may interfere with particle assembly, stability, or infectivity. Single amino acids or peptides can be fused directly to the N-terminus of the PVX $\mathrm{CP}$, whereas longer peptides that prevent particle assembly require the presence of wild-type PVX CPs to avoid steric hindrance, resulting in the formation of hybrid particles containing both wild-type CP and the fusion protein. This is generally achieved by inserting the Foot-and-mouth disease virus (FMDV) 2A sequence between the transgene and the $c p$ sequence, yielding a CP fusion protein, free target protein, and wild-type CP due to a ribosomal skip during translation (the overcoat method) [43-45]. The biochemical properties of peptides and proteins fused to the CP can also affect virus particle assembly, stability, or functionality (e.g., systemic spreading), including the number of serine/threonine [46] or tryptophan residues [47], and the isoelectric point ( $\mathrm{pI}$ ) $[47,48]$. A PVX-mCherry overcoat system for in vivo tumor imaging in mouse models was recently reported [37].

Although fluorescent proteins such as mCherry and green fluorescent protein (GFP) are routinely used as reporters for molecular interactions, they are dependent on $\mathrm{pH}$ and oxygen, and their large size (at least 240 amino acids) and complex structure make them more difficult to express [49-51]. The recently discovered monomeric fluorescent protein iLOV (light, oxygen, or voltage sensing) was engineered from the LOV2 domain of Arabidopsis thaliana phototropin 2 and can be fused to the movement protein of TMV for quantitative biological imaging applications [52-55]. The iLOV sequence is approximately half the size of mCherry thus reducing the genetic load on the recombinant viruses, and its reversible photobleaching properties make it ideal for the analysis of virus movement in plants $[52,55,56]$. Here, we compared the behavior of PVX-iLOV particles created by either direct fusion or the use of the FMDV 2A sequence, focusing on their long-distance movement and propensity for systemic infection and the morphology of the modified particles compared to wild-type PVX.

\section{Materials and Methods}

2.1. Construction of Plant Viral Vectors. The PVX-based vectors we used to produce recombinant particles displaying the iLOV polypeptide are shown in Figure 1(a). The iLOV sequence was amplified from source vector pSC1001a (Dr. S. Chapman, The James Hutton Institute, Dundee, Scotland) using the primers listed in Table 1 and was transferred to pCR2.1-TOPO as previously described [57]. An iLOV fragment was isolated from this intermediate vector using NheI and BspEI and was transferred to vector pTCXIIc [37] either as a direct fusion (replacing the mCherry and FMDV 2A genes) or as fusion via the FMDV $2 \mathrm{~A}$ sequence (replacing only the mCherry gene). The iLOV sequence was also inserted into pPVX-N-mCherry- $\mathrm{G}_{4} \mathrm{~S}-\mathrm{CP}$ (our unpublished data) to create an iLOV-CP fusion via a $\left(\mathrm{Gly}_{4} \mathrm{Ser}\right)_{3}$ linker $\left(\mathrm{G}_{4} \mathrm{~S}\right)$. The integrity of the resulting vectors pPVX-iLOVCP, pPVX-iLOV-2A-CP, and pPVX-iLOV-G 4 S-CP was tested by PCR and sequencing. The vectors were propagated in Escherichia coli strain $\mathrm{DH} 5 \alpha$ ready for the inoculation of Nicotiana benthamiana plants as previously described [57].

2.2. RNA and Protein Analyses. Total RNA was isolated from systemically infected $N$. benthamiana leaves using the RNeasy Plant Mini Kit (Qiagen, Hilden, Germany) and $3 \mu \mathrm{g}$ RNA samples were treated with $3 \mathrm{U}$ DNaseI (Thermo Fisher Scientific) as recommended. The corresponding cDNA was produced using M-MLV Reverse Transcriptase RNaseH Minus Point Mutant (Promega, Madison, USA). We mixed $1 \mu \mathrm{g}$ of the DNaseI-treated RNA with $0.5 \mu \mathrm{M}$ of the oligo-dT primer for hybrid PVX particles and $27 \mu \mathrm{l}$ DEPC-treated water. The mixture was heated to $80^{\circ} \mathrm{C}$ and then incubated for $10 \mathrm{~min}$ on ice to ensure primer annealing before adding $10 \mu \mathrm{l} 5 \mathrm{x}$ M-MLV reaction buffer, $8.5 \mu \mathrm{l}$ DEPC-treated water, $1 \mathrm{mM}$ dNTPs, and $1 \mu \mathrm{l}$ M-MLV. The cDNA synthesis reaction was carried out for $30 \mathrm{~min}$ at $40^{\circ} \mathrm{C}, 20 \mathrm{~min}$ at $45^{\circ} \mathrm{C}, 20 \mathrm{~min}$ at $50^{\circ} \mathrm{C}, 20 \mathrm{~min}$ at $55^{\circ} \mathrm{C}$, and $20 \mathrm{~min}$ at $70^{\circ} \mathrm{C}$. After reverse transcription, residual RNA was degraded with $1 \mu \mathrm{l} 10 \mathrm{mg} / \mathrm{ml} \mathrm{RNaseA}$ for $1 \mathrm{~h}$ at $37^{\circ} \mathrm{C}$. PCR was carried out with primers TGB-fw and CX4 and the products were resolved by $1.2 \%$ agarose gel electrophoresis 


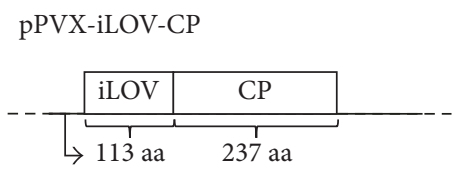

pPVX-iLOV-2A-CP

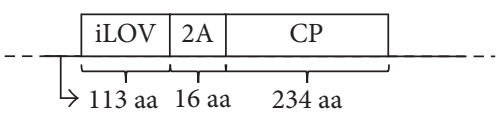

pPVX-iLOV-G ${ }_{4}$ S-CP

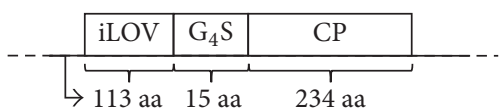

(a)

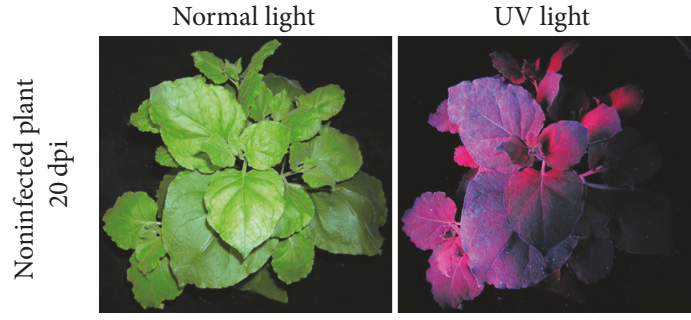

(b)

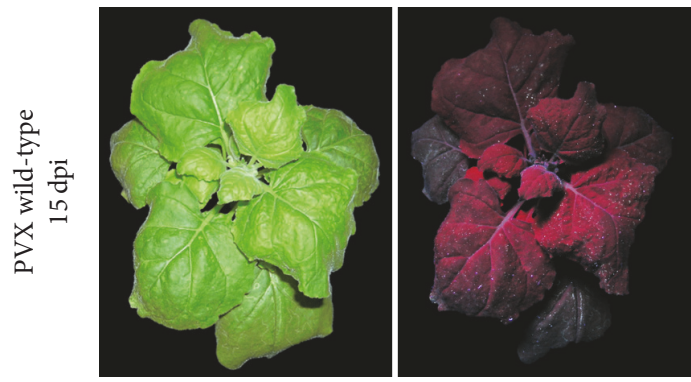

(c)

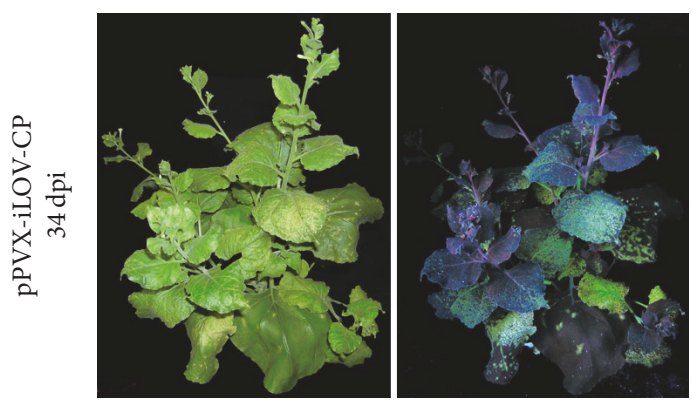

(d)

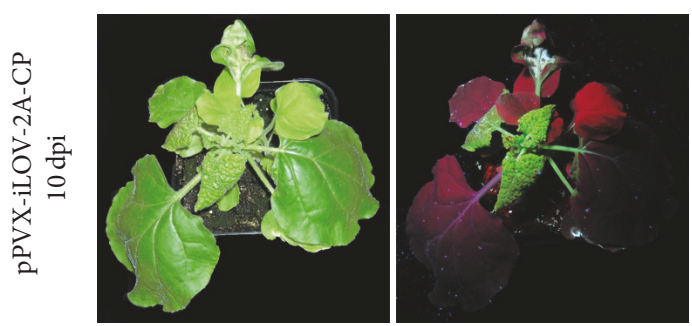

(e)

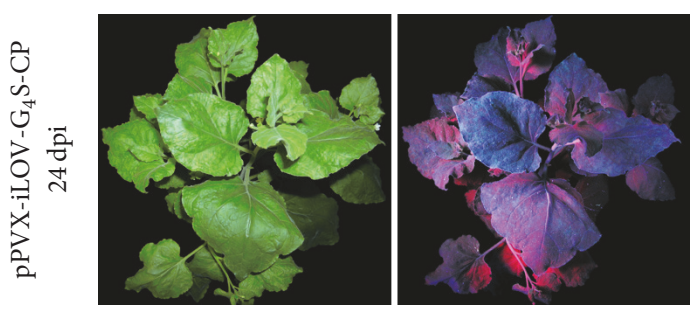

(f)

FIgURE 1: PVX-derived vectors for the expression of iLOV and the infection of $N$. benthamiana. (a) The iLOV coding sequence was added either as a direct fusion to the $5^{\prime}$-end of the PVX coat protein $(\mathrm{CP})$ gene, with a $\left(\mathrm{G}_{4} \mathrm{~S}\right)_{3}$ linker, or as a fusion to the FMDV $2 \mathrm{~A}$ sequence. The target genes are depicted as part of the complete viral genome. (b-f) Symptoms and detection of fluorescence in N. benthamiana plants inoculated with hybrid PVX. (b) Noninfected N. benthamiana plant and plants infected with (c) wild-type PVX, (d) pPVX-iLOV-CP, (e) pPVX-iLOV-2A-CP, and (f) pPVX-iLOV-G $\mathrm{S}_{4} \mathrm{CP}$ were displayed either under UV light or under normal light 10-34 days after inoculation (dpi) depending on the progress of infection. 
to confirm the integrity of the iLOV-CP and iLOV-2A-CP cDNAs.

RNA levels in PVX-infected leaves were determined by quantitative real-time PCR (qPCR). We mixed $5 \mu \mathrm{l}$ of recombinant PVX cDNA samples with $0.3 \mu \mathrm{M}$ each of primers CX $4 \mathrm{i}$ and CX8, $10 \mu \mathrm{l} 2 \mathrm{x}$ iQ ${ }^{\mathrm{TM}}$ SYBR Green ${ }^{\circledR}$ supermix (BioRad, Munich, Germany), and $3.8 \mu \mathrm{l}$ water. The qPCR program comprised three steps: $3 \mathrm{~min}$ at $95^{\circ} \mathrm{C}$ for polymerase activation and DNA denaturation and then 40 cycles of $15 \mathrm{~s}$ at $95^{\circ} \mathrm{C}$, $30 \mathrm{~s}$ at $55^{\circ} \mathrm{C}$, and $45 \mathrm{~s}$ at $72^{\circ} \mathrm{C}$ measured with SYBR Green. Finally, melting curves were constructed from $55^{\circ} \mathrm{C}$ to $95^{\circ} \mathrm{C}$ in $0.5^{\circ} \mathrm{C} / 2 \mathrm{~s}$ steps using primers for the $c p(\mathrm{CX} 4 \mathrm{i}$ and $\mathrm{CX} 8)$ and tgb (CX3i and CX9) as previously described [14]. Triplicate measurements were taken with samples from at least three different plants.

Proteins were extracted from systemically infected $N$. benthamiana leaves and were analyzed by SDS-PAGE [58] and western blot, with specific antibodies against iLOV and the PVX CP as previously described [57].

2.3. Confocal Microscopy. Systemic infection with recombinant PVX particles was visualized by confocal laser scanning microscopy using a Leica TCS SP instrument (Leica Microsystems, Wetzlar, Germany). We removed $1 \times 1 \mathrm{~cm}$ leaf pieces showing fluorescence and mounted them with the abaxial surface facing upwards onto glass microscope slides. An HCX PL APO $63.0 \times 5.00$ water-corrected objective was used with a drop of water placed directly on the coverslip to image viral cell-to-cell movement across the epidermal cell layer. The excitation and detection wavelengths for iLOV were $476 \mathrm{~nm}$ and $510-550 \mathrm{~nm}$, respectively. LCS software was used for image analysis, following import into Photoshop CS5 (Adobe Systems, Mountain View, USA) for contrast adjustments and overlay.

2.4. Purification of $i L O V$-Displaying Particles. Purified iLOV$\mathrm{CP}$ and iLOV-2A-CP virus particles were prepared as described in the protocol published by the International Potato Centre (Lima, Peru) with modifications as previously described [13]. Centrifugation with a sucrose cushion was omitted and the pellet was directly resuspended after clarification. Subsequent centrifugation was carried out at $7800 \times \mathrm{g}$ for $10 \mathrm{~min}$ at $4^{\circ} \mathrm{C}$ instead of $2000 \times \mathrm{g}$ for $5 \mathrm{~min}$ at $4^{\circ} \mathrm{C}$, and the second ultracentrifugation to sediment the virions was at least 3-4 h instead of $1 \mathrm{~h}$. The final clarification step was also omitted.

2.5. Transmission Electron Microscopy. Immunosorbent electron microscopy (ISEM) was carried out with viruscontaining plant extracts from systemically infected leaves or purified recombinant viruses. Pioloform-coated nickel grids (Plano, Wetzlar, Germany) were incubated on a drop of monoclonal antibody MAC58 against PVX (kindly provided by Professor L. Torrance, The James Hutton Institute) for $20 \mathrm{~min}$ at room temperature to capture the recombinant PVX particles. Immunogold decoration of captured or adsorbed particles with primary anti-PVX antibody or the anti-iLOV antiserum and secondary goat anti-rabbit (GAR) $15 \mathrm{~nm}$ gold conjugate (British BioCell, Cardiff, UK) and imaging was carried out as previously described [57].

\section{Results}

3.1. Vector Construction and Infection of Plants. Three different PVX-based expression constructs were prepared, joining the iLOV sequence to the $5^{\prime}$-end of the PVX $c p$ gene using different strategies: (a) a direct fusion, (b) via a $\left(\mathrm{Gly}_{4} \mathrm{Ser}\right)_{3}$ linker, and (c) via the FMDV 2A sequence (Figure 1(a)). Following the inoculation of $N$. benthamiana plants separately with each vector, plants infected with pPVX-iLOV-2A$\mathrm{CP}$ showed initial fluorescent spots at the inoculation site 4 days after inoculation (dpi) and systemic infection was observed $6 \mathrm{dpi}$, as revealed by the general green fluorescence. These plants also displayed more severe symptoms than typically observed for systemic infection with wild-type PVX, including mosaic patterns and dwarfing, and necrotic lesions appearing from 10 dpi onwards (Figures 1(c) and 1(e)). In contrast, plants infected with pPVX-iLOV-CP showed initial fluorescent spots at the inoculation site $8 \mathrm{dpi}$ or later. The long-distance movement of the virus was significantly delayed: systemic infection was not observed until 17-21 dpi (Figure 1(d)). Plants inoculated with the pPVX-iLOV-G $\mathrm{G}_{4} \mathrm{~S}-$ $\mathrm{CP}$ vector did not show any signs of systemic infection (Figure 1(f)).

Quantitative real-time PCR (qPCR) was carried out to determine the levels of $c p$ RNA in leaves from systemically infected N. benthamiana plants (Figure 2). Total RNA was isolated from leaves showing iLOV fluorescence, cDNA synthesis was carried out and the integrity of the modified PVX sequence was verified by a control PCR with primers TGB-fw and CX4, amplifying a region between the triple gene block protein 3 (tgbp3) and $c p$ genes (Figure 2(a)). We then determined the relative levels of the $\operatorname{tgb} p 3$ and $c p$ RNAs with the housekeeping gene $P P 2 A$ used as a reference. The amount of ilov and $c p$ RNA was compared to the amount of tgb3 RNA, which can be found in the PVX genomic RNA (gRNA) and subgenomic RNAs (sgRNAs) 1 and 2 but not sgRNAs 3. This allowed a direct correlation between the iLOV-(2A)-CP RNA level and the total amount of PVX RNA. The quantity of $t g b p 3$ and $c p$ RNA was correlated to $P P 2 A$ mRNA and the relative amount of $c p$ to $\operatorname{tg} b 3$ was calculated and compared. We observed higher relative $c p$ RNA levels for the iLOV-2A-CP fusion than for the iLOV-CP direct fusion (Figure 2(b)). This was consistent with the rapid infection and severe symptoms in plants infected with pPVX-iLOV-2A-CP compared to the slower systemic infection with pPVX-iLOVCP.

3.2. Analysis of Recombinant PVX Particles Displaying iLOV. Extracts were prepared from leaves containing the pPVXiLOV-CP and pPVX-iLOV-2A-CP fusion proteins for analysis by SDS-PAGE and western blot. The iLOV-CP and iLOV-2A-CP fusion proteins were detected with the antiPVX antibody and the anti-iLOV antiserum with molecular weights of 38.0 and $39.9 \mathrm{kDa}$, respectively, as expected (Figures 3(b) and 3(c) highlighted with asterisks). A $25 \mathrm{kDa}$ band representing the wild-type PVX CP was also detected 


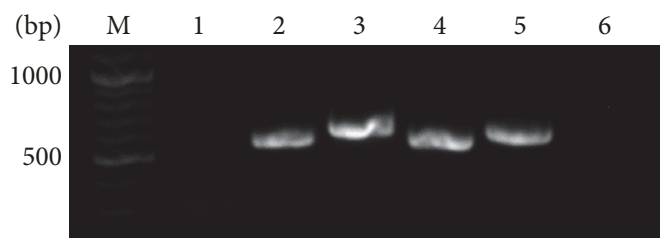

(a)

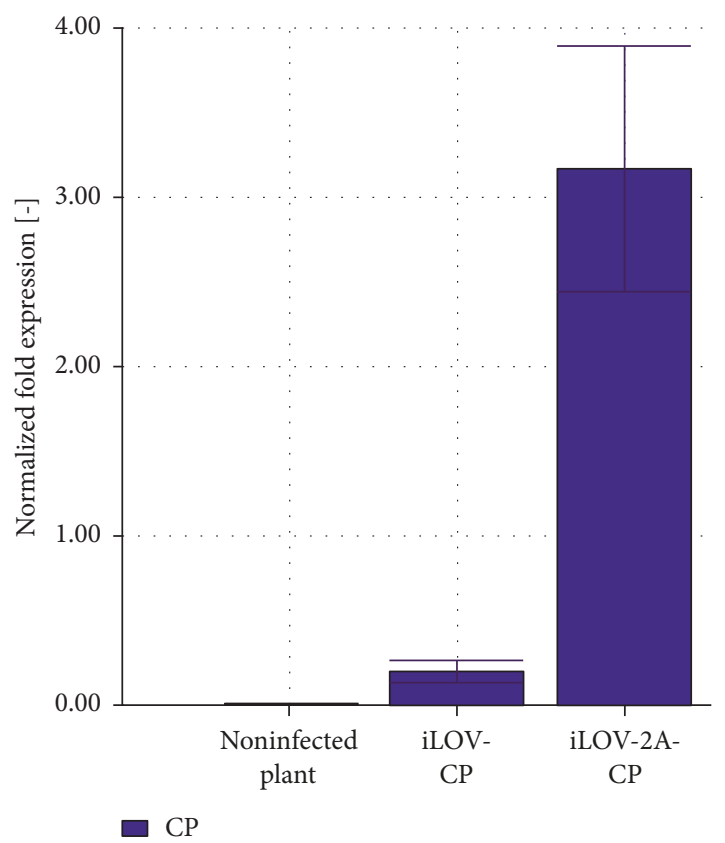

(b)

FIGURE 2: Analyses of RNA levels in systemically infected $N$. benthamiana leaves by reverse transcription PCR and qPCR. (a) Reverse transcription PCR of isolated RNA used for qPCR. M: Gene Ruler 100 bp Plus DNA ladder (Thermo Fisher Scientific), 1: negative control, RNA from noninfected $N$. benthamiana, 2: pPVX-iLOV-CP infected, 3: pPVX-iLOV-2A-CP infected, 4: positive control, plasmid pPVX-iLOV-CP, 5: positive control, plasmid pPVX-iLOV-2A-CP, and 6: negative control, DEPC-treated water. (b) qPCR analysis. Normalized fold expression is shown in relation to the $\operatorname{tg} b p 3$ and $c p$ genes. Measurements were performed in triplicate and repeated with samples from at least three different plants. Error bars show standard deviations of the $2^{-\Delta \Delta C_{T}}$ values.

in the samples containing iLOV-2A-CP because fusion to the FMDV 2A sequence is known to cause a ribosomal skip (Figure 3(b)). However, the CP was also detected by the antiiLOV antiserum (Figure 3(c)). The $13.5 \mathrm{kDa}$ free iLOV protein (highlighted with an arrow) was also visible in the western blot probed with anti-iLOV antiserum (Figure 3(c)) as well as in the polyacrylamide gel under UV light (Figure 3(d)). Densitometric analysis of iLOV bands in the anti-iLOV western blot showed a ratio of approximately 7 to 3 for free iLOV to the iLOV-2A-CP fusion protein.

The ability of the fusion proteins to assemble into PVX particles was confirmed by electron microscopy. PVX particles were immunocaptured from leaf extracts using monoclonal antibody MAC58, detected with a primary anti-PVX antibody and decorated with GAR $15 \mathrm{~nm}$ gold conjugates (Figures 3(e)-3(h)). Typically, wild-type PVX particles are flexible $515 \times 13.5 \mathrm{~nm}$ structures (Figure $3(\mathrm{~g})$ ), but iLOV-CP and iLOV-2A-CP particles showed a different morphology (Figures 3(e) and 3(f)). These particles were of the same size as wild-type particles but were intertwined, resulting in a morphology similar to that described for PVX particles with $\mathrm{N}$-terminal coat protein truncations [59].

3.3. Localization of iLOV within the Plant Cell. To gain insight into the cell-to-cell movement of hybrid PVX particles, leaves systemically infected with pPVX-iLOV-CP and pPVX-iLOV2A-CP were studied by confocal laser scanning microscopy (Figure 4). The iLOV fluorescence was concentrated in certain areas of the cell wall, which potentially indicates the cell-to-cell movement of PVX-iLOV particles through the plasmodesmata. The fluorescence profile (Figures 4(c) and $4(f))$ indicated that the virus uses these intercellular links to cross the plant cell wall $[60,61]$. We also observed large viral replication complexes (VRCs) within cells, typically one per infected cell $[62,63]$. In leaves infected with pPVX-iLOV$2 \mathrm{~A}-\mathrm{CP}$, we detected free iLOV protein in the cytoplasm and in the nucleus, reflecting the ribosomal skip at the FMDV 2A sequence (Figure 4(f)). The fluorescence of the iLOV-CP direct fusion led to a more precise localization of the hybrid virus within the plasmodesmata.

3.4. Purification and Immunogold Labeling of Virus Particles. PVX particles displaying iLOV were purified with yields of 136-206 mg per kg of infected leaf material by adapting the purification protocol for wild-type PVX particles developed by the International Potato Centre. The different pooled fractions were tested for the presence of iLOV-CP and iLOV2A-CP by western blot (Figure 5). Both the polyclonal antiPVX antibody and the anti-iLOV antiserum detected some degradation products but also intact proteins with the anticipated molecular weights of the iLOV-CP and iLOV-2A-CP fusion proteins (Figures 5(b) and 5(c)). The iLOV-CP fusion protein is only detected in very low amounts with an antiPVX antibody, probably due to the low amounts of purified particles and protein degradation. The anti-iLOV antiserum also detected bands of the wild-type PVX CP, and thus it was necessary to find out whether the antiserum was able to also detect wild-type PVX particles by electron microscopy. Purified iLOV-CP, iLOV-2A-CP, and wild-type PVX virions were directly adsorbed onto the grids (Figure $5(\mathrm{~d})$ ) or captured using monoclonal antibody MAC58 (Figure 5(e)). The fusion proteins were detected by the primary anti-iLOV antiserum and labeled with the secondary GAR $15 \mathrm{~nm}$ gold conjugate. We found that only PVX particles displaying the iLOV protein on the surface were labeled, not the wildtype PVX particles. Thus, scattered single gold particles are most likely background and not bound to particles. These experiments also confirmed that the heterologous fusion protein is accessible even if the recombinant virions are intertwined.

\section{Discussion}

The biological compatibility and multivalency of genetically and chemically addressable sites on virus CPs have resulted in 


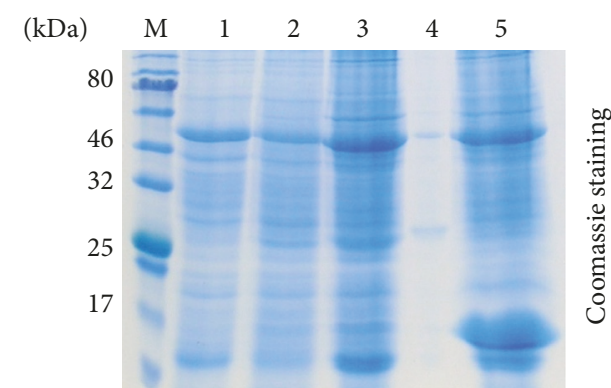

(a)

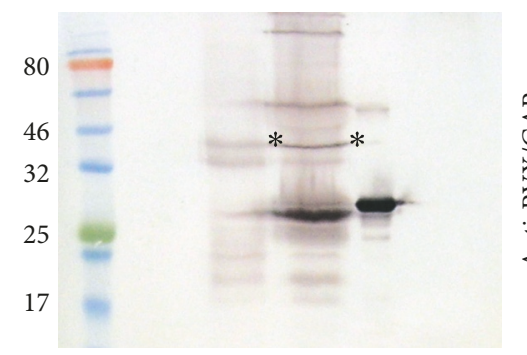

(b)

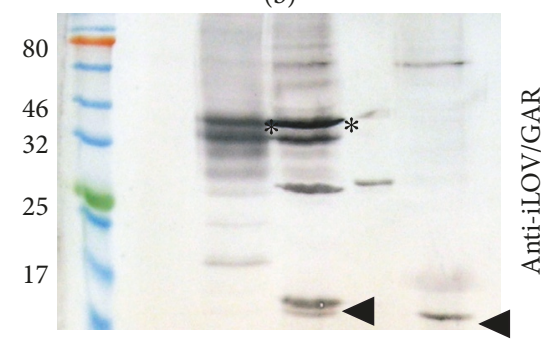

(c)

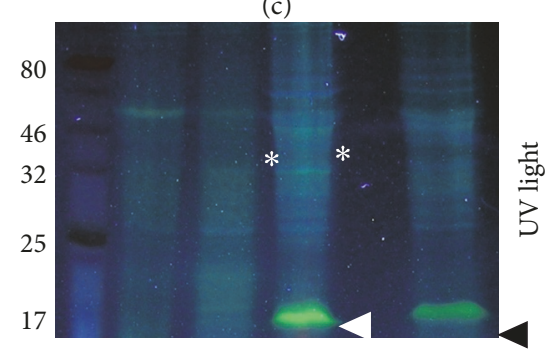

(d)

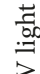

$\frac{20}{3}$
iLOV-CP

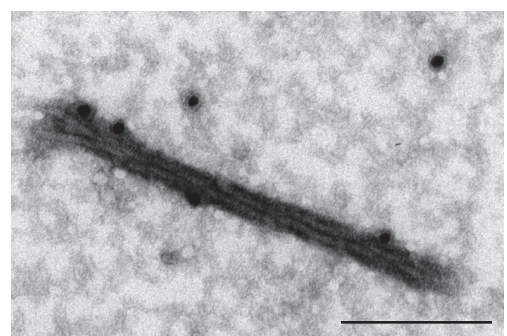

(e)

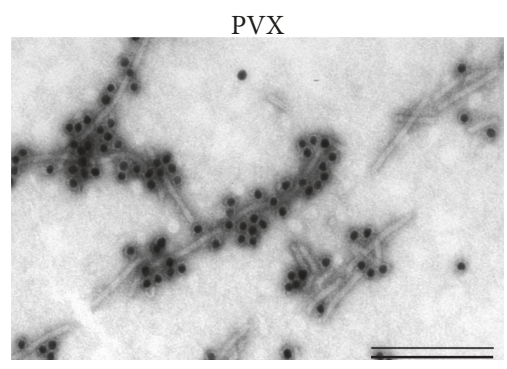

(g)

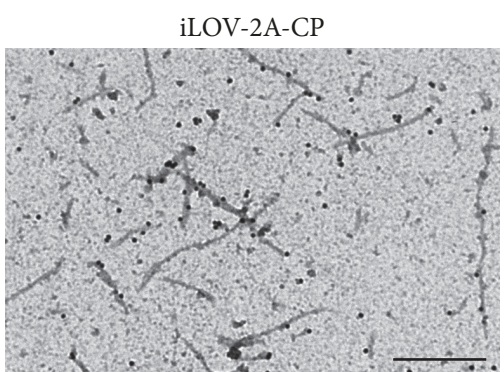

(f)

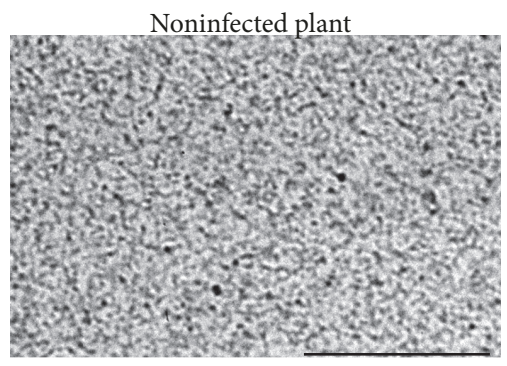

(h)

FIGURE 3: Analyses of PVX-infected N. benthamiana leaves expressing iLOV. (a-d) Leaf extracts (20 $\mu$ l) were separated by SDS-PAGE and proteins were (a) stained with Coomassie Brilliant Blue, (b, c) transferred onto a nitrocellulose membrane for western blotting, or (d) detected under UV light. M: P7712 Prestained Protein Standard (NEB), 1: negative control, plant extract from noninfected N. benthamiana leaves, 2: plant extract from pPVX-iLOV-CP infected leaves, 3: plant extract from pPVX-iLOV-2A-CP infected leaves, 4: positive control, PVX particles, and 5: positive control, plant extract of iLOV expressed by TMV-derived vector under control of a subgenomic promoter-like sequence [57]. Antibody detection: (b) anti-PVX and GAR ${ }^{\mathrm{AP}}$ and (c) anti-iLOV and GAR ${ }^{\mathrm{AP}}$. iLOV-CP and iLOV-2A-CP fusion proteins are highlighted with asterisks, and the free iLOV polypeptide is highlighted with an arrow. (e-h) Electron micrographs of leaf extracts expressing recombinant PVX particles displaying iLOV. (e) iLOV-CP, (f) iLOV-2A-CP, and (g) PVX particles captured with MAC58, detected with antiPVX, and labeled with GAR $15 \mathrm{~nm}$ gold conjugate. Bar = (e) $200 \mathrm{~nm},(\mathrm{f}, \mathrm{g}) 500 \mathrm{~nm}$, and (h) $1 \mu \mathrm{m}$.

a broad range of applications for plant virus nanoparticles. In this study, PVX-derived vectors (Figure 1(a)) were generated to present the monomeric fluorescent protein iLOV on the surface of PVX particles by fusing it to the $5^{\prime}$-terminus of the PVX CP directly, via a FMDV 2A sequence (overcoat), or via a sequence coding for a flexible glycine-serine-rich linker. The direct fusion (pPVX-iLOV-CP) and overcoat (pPVX-iLOV2A-CP) constructs were able to achieve systemic infection whereas the linker construct (pPVX-iLOV-G 4 S-CP) was not, most likely due to size limitation $[15,48,64,65]$, and the latter was therefore excluded from further experiments. To exclude the possibility that the flexibility of the $\mathrm{G}_{4} \mathrm{~S}$ linker enables iLOV to move between the CP subunits and prevents particle assembly, we replaced the $\mathrm{G}_{4} \mathrm{~S}$ linker with the more rigid $\mathrm{AK}_{3} \mathrm{~A}$ linker (three copies of the sequence AKKKA). The plants showed neither green fluorescence in 


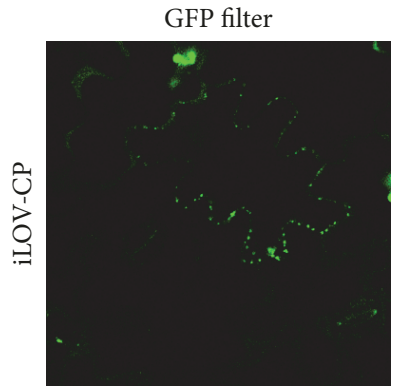

(a)

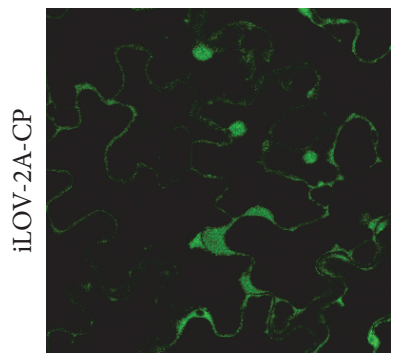

(d)

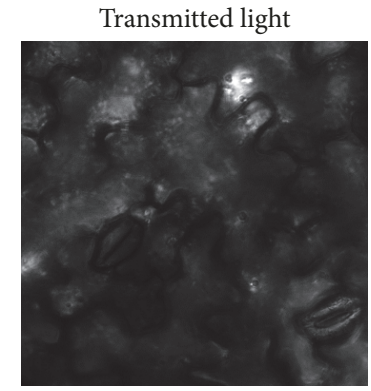

(b)

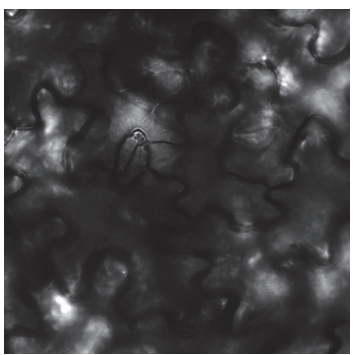

(e)
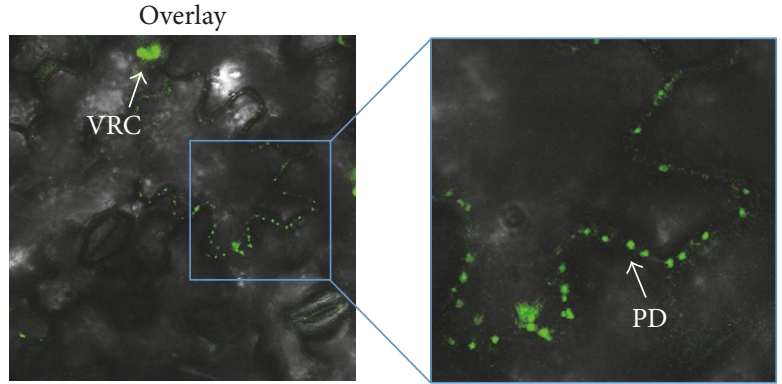

(c)

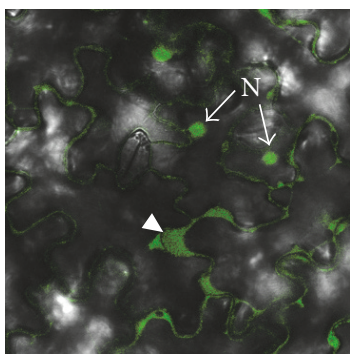

(f)

FIgURE 4: Detection of green fluorescence in epidermal cells from $N$. benthamiana leaves systemically infected with pPVX-iLOV-CP and pPVX-iLOV-2A-CP. The iLOV fluorescence was observed by confocal laser scanning microscopy. The hybrid particles indicate cell-to-cell movement at plasmodesmata (PD) and viral replication complexes (VRCs). For iLOV-2A-CP there is also free iLOV visible in the cytoplasm $(\triangleright)$. N: nucleus.

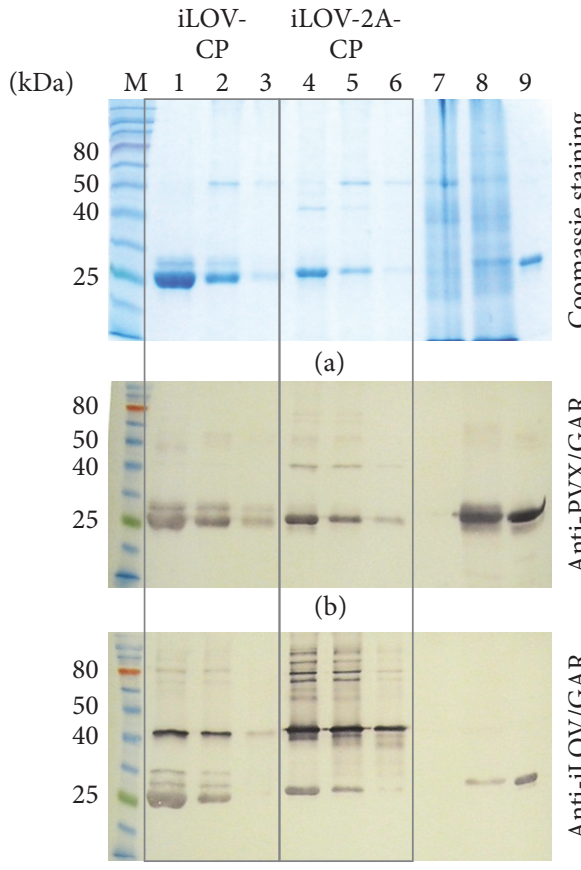

(c)

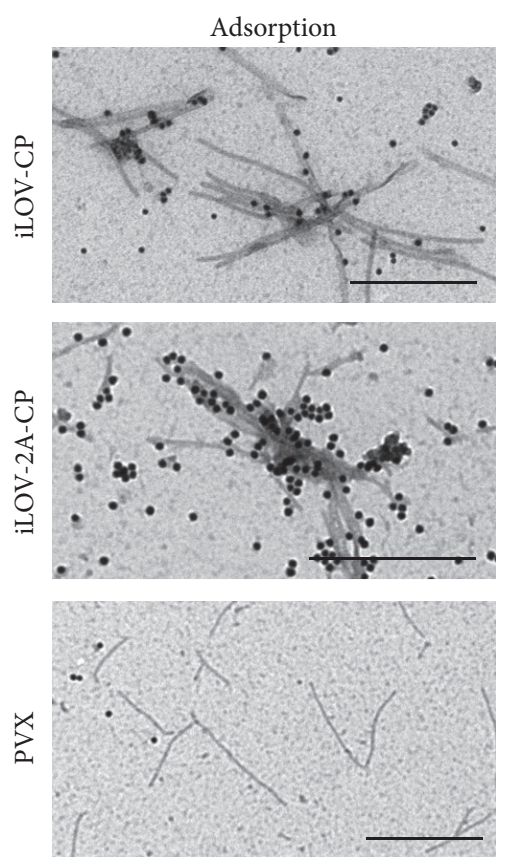

(d)

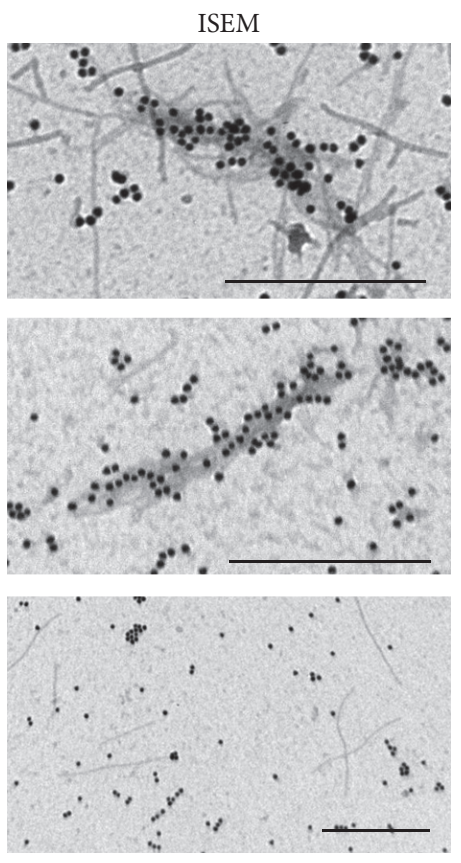

(e)

FIgure 5: Analyses of purified iLOV-CP and iLOV-2A-CP particles. (a-c) Purified PVX particles (5 $\mu$ g) displaying iLOV separated by SDSPAGE. M: P7711 Prestained Protein Standard (NEB), 1: iLOV-CP sample 1, 2: iLOV-CP sample 2, 3: iLOV-CP sample 3, 4: iLOV-2A-CP sample 1, 5: iLOV-2A-CP sample 2, 6: iLOV-2A-CP sample 3, 7: negative control, noninfected $N$. benthamiana leaf extract, 8: PVX-GFP-2A$\mathrm{CP}$ infected leaf extract, and 9: positive control, PVX particles. Antibody detection: (b) anti-PVX and GAR ${ }^{\mathrm{AP}}$ and (c) anti-iLOV and GAR ${ }^{\mathrm{AP}}$. (d-e) Transmission electron microscopy of recombinant particles. Adsorption: detection with anti-iLOV and decoration with GAR $15 \mathrm{~nm}$ gold conjugate, ISEM: capture with monoclonal MAC58, detection with anti-iLOV, and decoration with GAR $15 \mathrm{~nm}$ gold conjugate. Bar = $500 \mathrm{~nm}$. 
inoculated leaves nor systemic infection at 28 dpi (data not shown).

Systemic infection with pPVX-iLOV-CP was delayed and the infection symptoms were mild, whereas rapid systemic infection was established following inoculation with pPVX-iLOV-2A-CP and the infection symptoms were severe, including necrosis (Figures $1(\mathrm{~d})$ and $1(\mathrm{e})$ ). This may reflect the ability of the iLOV protein to promote the synthesis of reactive oxygen species [66]. Following inoculation with pPVXiLOV-2A-CP, the iLOV polypeptide was overexpressed as a fusion protein but also as a free protein due to the overcoat principle, potentially triggering the accumulation of greater quantities of reactive oxygen species in these plants compared to those infected with pPVX-iLOV-CP (Figure 1(e)).

When certain peptides or proteins are fused to plant virus CPs, the assembly of the virion is sterically or electrostatically inhibited and systemic movement prevented [15, 48, 64, 65]. However, fusing the 113-amino-acid iLOV polypeptide directly to the N-terminus of the PVX CP still allows the assembly of hybrid virions which can move from cell-to-cell and achieve systemic infections via translocation through the vascular system. The iLOV polypeptide is much larger than the largest peptides that have been displayed by direct $\mathrm{CP}$ fusion in other plant viruses, for example, 23 amino acids for Tobacco mosaic virus (TMV) [64], 30 amino acids for Plum pox virus [67], and 50 amino acids for Cowpea mosaic virus $[65,68]$. With the help of a 15-residue linker, a 133amino-acid fragment of staphylococcal protein A has been displayed on the surface of TMV [69], whereas the largest peptide expressed on the surface of PVX until the current report was 14 amino acids in length [12]. Fusion peptides larger than 40 amino acids usually require the presence of the wild-type PVX CP to assemble into intact hybrid particles, which is most easily achieved by incorporating the FMDV $2 \mathrm{~A}$ sequence [43] as shown by the successful display of the $45 \mathrm{kDa}$ VP6 rotavirus capsid protein (397 amino acids) on PVX [11]. The ratio of fusion protein to wild-type CP cannot be predicted accurately [70,71], although using different variants of $2 \mathrm{~A}$ sequences provides a degree of control [71]. As a tool for the bioimaging of viral cell-to-cell movement, fluorescent proteins should be densely arrayed on the virus surface to achieve a bright signal, as shown for the iLOV-CP direct fusion but not for the iLOV-2A-CP construct, which also generated diffuse fluorescence mainly caused by the free iLOV polypeptide (Figure 4).

We investigated the $c p$ RNA level in relation to the $\operatorname{tg} b p 3$ RNA by qPCR because the PVX $\operatorname{tg} b p 3$ sequence is found on the gRNA and all sgRNAs except that carrying the $c p$ gene, whereas the $c p$ sequence is found on the gRNA and all sgRNAs. The comparison of $c p$ and tgbp3 RNA levels therefore provides an estimation of $c p$ RNA levels with a builtin internal control. The level of iLOV-CP RNA was lower than that of iLOV-2A-CP RNA (Figure 2), explaining why the iLOV-CP particles spread more slowly through the plant. Our data suggest there are lower levels of sgRNA3 and thus lower levels of the iLOV-CP fusion protein, which can assemble to intact particles for long-distance movement. A certain ratio between the number of assembled particles and the quantity of free PVX CP [46] is necessary for viral cell-to-cell movement and long-distance transport [47, 61, 72-74]. This is why fewer iLOV-CP particles assembled compared to iLOV$2 \mathrm{~A}-\mathrm{CP}$ particles, thus reducing the viral load. These results are consistent with the observed delayed systemic spread of iLOV-CP particles and the rapid infection and severe symptoms caused by iLOV-2A-CP. However, the differences of sgRNA levels are unexpected, given that the iLOV sequence is incorporated into the viral genome in the same way in both constructs. The only difference is the $2 \mathrm{~A}$ sequence introduced between the iLOV and CP sequences. The introduction of the $2 \mathrm{~A}$ sequence in this construct therefore seems to be more favorable even for sgRNA levels.

Some PVX coat proteins with $\mathrm{N}$-terminal extension peptides cannot form particles due to steric inhibition [43], the number of serine/threonine [46] or tryptophan residues [47], or the $\mathrm{pI}$ of the fusion peptide [47, 48]. If fusion peptides have a $\mathrm{pI}$ value in the range 5.2-9.2, the resulting particles can move systemically [47], although basic amino acids reduce the fitness of the virus resulting in the selection of better performing mutants [48]. Only $\sim 13 \%$ of the amino acids in the iLOV peptide are positively charged and the iLOV-CP fusion has a $\mathrm{pI}$ of 5.8. There was no reversion to the wildtype PVX $c p$ sequence at $34 \mathrm{dpi}$ as reported for iLOV fusions to the TMV CP [57]. However, we observed proteolytic degradation of the purified iLOV-CP particles in western blots probed with the polyclonal anti-PVX antibody and antiiLOV antiserum after particle purification (Figures 5(b) and 5(c)). The particles might be degraded during the purification process due to a lower stability of the particles in general. However, the extracts contained larger quantities of the fusion products than the virus purification (compare Figures $3(\mathrm{~b})$ and $3(\mathrm{c})$ and $5(\mathrm{~b})$ and 5(c)). In addition to protein degradation, we might have lost particles with a high ratio of iLOV-CP fusion to wild-type CP during the gradient purification. Particles with a greater proportion of fusion proteins accumulate in the gradient with a lower sucrose concentration and might be lost due to low visibility in the SDS gels of the gradient fractions. This could probably be prevented by adapting the purification protocol accordingly.

The presence of iLOV-decorated PVX particles in systemically infected leaves was confirmed by western blots and transmission electron microscopy (Figures 3 and 5). Wild-type PVX particles are filamentous rods, $515 \mathrm{~nm}$ in length-they are flexible but exist as discrete units. In contrast, the iLOV-CP and iLOV-2A-CP particles were similar in structure but the filaments tended to intertwine. A similar morphology was reported when PVX particles were assembled from N-terminally truncated CPs lacking codons 7-31 of the $c p$ gene [59]. These results show that the N-terminus is required to modulate intramolecular and/or intermolecular interactions. Approximately $37 \%$ of the residues in the iLOV protein are hydrophobic, so intermolecular hydrophobic interactions may be responsible for the intertwined morphology.

Confocal laser scanning microscopy revealed that the recombinant iLOV-CP and iLOV-2A-CP particles were potentially able to pass between epidermal cells, as indicated by the presence of a fluorescent signal in the plasmodesmata (Figure 4). Similarly localized CPs with 2A fusions of 
fluorescent proteins have been reported in PVX movement studies $[60,61,75]$. We also observed one large fluorescent VRC per infected cell, which is frequently observed in established infections $[60,62,63]$. These so-called "virus factories" coordinate the infection processes [62]. Additional diffuse fluorescence was observed in epidermal cells infected with the pPVX-iLOV-2A-CP construct, representing the presence of free iLOV polypeptide. Free iLOV was also detected in western blots, with a ratio of 7 to 3 relative to the fusion protein. This leads to a high background of free iLOV in the cells, preventing the detailed analysis of CP localization. These findings emphasize the advantage of direct fusions of fluorescent proteins to the target protein.

Fluorescent proteins can provide insight into many cellular processes and interactions but also suffer from drawbacks such as their complex structure, large size, $\mathrm{pH}$, and oxygen dependence $[50,51]$. The iLOV polypeptide has spectral characteristics similar to GFP [76], but it is monomeric, has a lower molecular weight, is more photostable, and undergoes reversible photobleaching, the latter providing advantages for imaging applications $[52,55]$. The presentation of the iLOV fluorescent protein on the surface of filamentous PVX offers a promising new imaging tool, particularly for the investigation of PVX infections. More specifically, these hybrid virions may be able to provide insight into the subcellular location of CP synthesis and the distribution and packaging of gRNA. The iLOV polypeptide can also be used for antiviral drug screening [77].

\section{Conclusion}

We have demonstrated that the 113-amino-acid fluorescent protein iLOV can be directly fused to the N-terminus of the PVX coat protein without the help of a flexible linker and is displayed on the particle surface. Because the iLOV protein has several advantages over other fluorescent proteins, it will be useful not only for the analysis of VRCs and longdistance virus movement, which currently relies on the production of overcoat structures, but also as a new platform for the molecular imaging of tumors. We recently reported an mCherry PVX overcoat system for tumor imaging in mouse models [37]. Our PVX-iLOV particles generated a strong fluorescent signal due to the dense array of iLOV polypeptides, offering a highly sensitive new modality for imaging applications.

\section{Conflicts of Interest}

The authors declare no conflicts of interest regarding the publication of this paper.

\section{Acknowledgments}

The authors acknowledge the excellent technical assistance of Karolin Richter. They thank Dr. Sean Chapman (The James Hutton Institute, Dundee, Scotland) for the kind gift of the iLOV sequence and Professor John Christie (Institute of Molecular Cell and Systems Biology, University of Glasgow, Scotland) for the anti-iLOV antiserum. The authors thank
Dr. Jens Tilsner for helpful discussions and Dr. Richard M Twyman for critically reading the manuscript. This research was funded by the Excellence Initiative of the German Federal and State Governments (Gefördert durch Mittel der Exzellenzinitiative des Bundes und der Länder).

\section{References}

[1] C. Lico, E. Benvenuto, and S. Baschieri, "The two-faced potato virus X: from plant pathogen to smart nanoparticle," Frontiers in Plant Science, vol. 6, article 1009, 2015.

[2] J. L. M. C. Geelen, A. Van Kammen, and B. J. M. Verduin, "Structure of the capsid of cowpea mosaic virus. The chemical subunit: molecular weight and number of subunits per particle," Virology, vol. 49, no. 1, pp. 205-213, 1972.

[3] P. J. Butler, "The current picture of the structure and assembly of tobacco mosaic virus," Journal of General Virology, vol. 65, part 2, pp. 253-279, 1984.

[4] A. Kendall, W. Bian, A. Maris et al., "A common structure for the potexviruses," Virology, vol. 436, no. 1, pp. 173-178, 2013.

[5] T. Lin, Z. Chen, R. Usha et al., "The refined crystal structure of cowpea mosaic virus at 2.8 Å resolution," Virology, vol. 265, no. 1, pp. 20-34, 1999.

[6] X. Agirrezabala, E. Méndez-López, G. Lasso, M. A. SánchezPina, M. Aranda, and M. Valle, "The near-atomic cryoEM structure of a flexible filamentous plant virus shows homology of its coat protein with nucleoproteins of animal viruses," eLife, vol. 4, Article ID el1795, 2015.

[7] M. G. Rossmann, "Structure of viruses: a short history," Quarterly Reviews of Biophysics, vol. 46, no. 2, pp. 133-180, 2013.

[8] A. M. Wen and N. F. Steinmetz, "Design of virus-based nanomaterials for medicine, biotechnology, and energy," Chemical Society Reviews, vol. 45, no. 15, pp. 4074-4126, 2016.

[9] S. Chapman, T. Kavanagh, and D. Baulcombe, "Potato virus X as a vector for gene expression in plants," The Plant Journal, vol. 2, no. 4, pp. 549-557, 1992.

[10] D. C. Baulcombe, S. Chapman, and S. Santa Cruz, "Jellyfish green fluorescent protein as a reporter for virus infections," The Plant Journal, vol. 7, no. 6, pp. 1045-1053, 1995.

[11] G. J. O’Brien, C. J. Bryant, C. Voogd, H. B. Greenberg, R. C. Gardner, and A. R. Bellamy, "Rotavirus VP6 expressed by PVX vectors in Nicotiana benthamiana coats PVX rods and also assembles into viruslike particles," Virology, vol. 270, no. 2, pp. 444-453, 2000.

[12] K. Uhde, R. Fischer, and U. Commandeur, "Expression of multiple foreign epitopes presented as synthetic antigens on the surface of Potato virus X particles," Archives of Virology, vol. 150, no. 2, pp. 327-340, 2005.

[13] K. Uhde-Holzem, V. Schlösser, S. Viazov, R. Fischer, and U. Commandeur, "Immunogenic properties of chimeric potato virus $\mathrm{X}$ particles displaying the hepatitis $\mathrm{C}$ virus hypervariable region I peptide R9," Journal of Virological Methods, vol. 166, no. 1-2, pp. 12-20, 2010

[14] C. Dickmeis, R. Fischer, and U. Commandeur, "Potato virus Xbased expression vectors are stabilized for long-term production of proteins and larger inserts," Biotechnology Journal, vol. 9, no. 11, pp. 1369-1379, 2014.

[15] R. L. Toth, S. Chapman, F. Carr, and S. S. Cruz, "A novel strategy for the expression of foreign genes from plant virus vectors," FEBS Letters, vol. 489, no. 2-3, pp. 215-219, 2001. 
[16] A. M. Zelada, G. Calamante, M. de la Paz Santangelo et al., "Expression of tuberculosis antigen ESAT-6 in Nicotiana tabacum using a potato virus X-based vector," Tuberculosis, vol. 86, no. 3-4, pp. 263-267, 2006.

[17] K. Uhde-Holzem, M. McBurney, B. D. B. Tiu et al., "Production of immunoabsorbent nanoparticles by displaying singledomain Protein A on Potato Virus X," Macromolecular Bioscience, vol. 16, no. 2, pp. 231-241, 2016.

[18] E. S. Mardanova, E. A. Blokhina, L. M. Tsybalova, H. Peyret, G. P. Lomonossoff, and N. V. Ravin, "Efficient transient expression of recombinant proteins in plants by the novel pEff vector based on the genome of potato virus X," Frontiers in Plant Science, vol. 8 , article 247, 2017.

[19] M. J. Huisman, H. J. Linthorst, J. F. Bol, and J. C. Cornelissen, "The complete nucleotide sequence of potato virus $\mathrm{X}$ and its homologies at the amino acid level with various plus-stranded RNA viruses," Journal of General Virology, vol. 69, part 8, pp. 1789-1798, 1988.

[20] B. E. Orman, R. M. Celnik, A. M. Mandel, H. N. Torres, and A. N. Mentaberry, "Complete cDNA sequence of a South American isolate of potato virus X," Virus Research, vol. 16, no. 3, pp. 293-305, 1990.

[21] K. G. Skryabin, A. S. Kraev, S. Y. Morozov et al., “The nucleotide sequence of potato virus x RNA," Nucleic Acids Research, vol. 16, no. 22, pp. 10929-10930, 1988.

[22] N. Sonenberg, A. J. Shatkin, R. P. Ricciardi, M. Rubin, and R. M. Goodman, "Analysis of terminal structures of RNA from potato virus X," Nucleic Acids Research, vol. 5, no. 7, pp. 2501-2512, 1978.

[23] S. Y. Morozov, L. I. Lukasheva, B. K. Chernov, K. G. Skryabin, and J. G. Atabekov, "Nucleotide sequence of the open reading frames adjacent to the coat protein cistron in potato virus $\mathrm{X}$ genome," FEBS Letters, vol. 213, no. 2, pp. 438-442, 1987.

[24] J. Sober, L. Jarvekulg, I. Toots, J. Radavsky, R. Villems, and M. Saarma, "Antigenic Characterization of Potato Virus X with Monoclonal Antibodies," Journal of General Virology, vol. 69, no. 8, pp. 1799-1807, 1988.

[25] L. A. Baratova, N. I. Grebenshchikov, E. N. Dobrov et al., "The organization of potato virus $\mathrm{X}$ coat proteins in virus particles studied by tritium planigraphy and model building," Virology, vol. 188, no. 1, pp. 175-180, 1992.

[26] L. A. Baratova, N. I. Grebenshchikov, A. V. Shishkov et al., "The topography of the surface of potato virus X: Tritium planigraphy and immunology analysis," Journal of General Virology, vol. 73, part 2, pp. 229-235, 1992.

[27] M. A. Nemykh, A. V. Efimov, V. K. Novikov et al., "One more probable structural transition in potato virus $\mathrm{X}$ virions and a revised model of the virus coat protein structure," Virology, vol. 373, no. 1, pp. 61-71, 2008.

[28] L. Parker, A. Kendall, and G. Stubbs, "Surface features of potato virus X from fiber diffraction," Virology, vol. 300, no. 2, pp. 291295, 2002.

[29] G. P. Lomonossoff and D. J. Evans, "Applications of plant viruses in bionanotechnology," in Plant Viral Vectors, vol. 375 of Current Topics in Microbiology and Immunology, pp. 61-87, Springer, Berlin, Germany, 2011.

[30] J. N. Culver, A. D. Brown, F. Zang, M. Gnerlich, K. Gerasopoulos, and R. Ghodssi, "Plant virus directed fabrication of nanoscale materials and devices," Virology, vol. 479-480, pp. 200-212, 2015.
[31] J. F. Steele, H. Peyret, K. Saunders et al., "Synthetic plant virology for nanobiotechnology and nanomedicine," Wiley Interdisciplinary Reviews: Nanomedicine and Nanobiotechnology, vol. 9, no. 4, Article ID e1447, 2017.

[32] N. P. Montague, E. C. Thuenemann, P. Saxena, K. Saunders, P. Lenzi, and G. P. Lomonossoff, "Recent advances of cowpea mosaic virus-based particle technology," Human Vaccines \& Immunotherapeutics, vol. 7, no. 3, pp. 383-390, 2011.

[33] F. M. Brunel, J. D. Lewis, G. Destito et al., "Hydrazone ligation strategy to assemble multifunctional viral nanoparticles for cell imaging and tumor targeting," Nano Letters, vol. 10, no. 3, pp. 1093-1097, 2010.

[34] K. L. Lee, L. C. Hubbard, S. Hern, I. Yildiz, M. Gratzl, and N. F. Steinmetz, "Shape matters: The diffusion rates of TMV rods and CPMV icosahedrons in a spheroid model of extracellular matrix are distinct," Biomaterials Science, vol. 1, no. 6, pp. 581$588,2013$.

[35] J. D. Lewis, G. Destito, A. Zijlstra et al., "Viral nanoparticles as tools for intravital vascular imaging," Nature Medicine, vol. 12, no. 3, pp. 354-360, 2006.

[36] M. Manchester and P. Singh, "Virus-based nanoparticles (VNPs): Platform technologies for diagnostic imaging," Advanced Drug Delivery Reviews, vol. 58, no. 14, pp. 1505-1522, 2006.

[37] S. Shukla, C. Dickmeis, A. S. Nagarajan, R. Fischer, U. Commandeur, and N. F. Steinmetz, "Molecular farming of fluorescent virus-based nanoparticles for optical imaging in plants, human cells and mouse models," Biomaterials Science, vol. 2, no. 5, pp. 784-797, 2014.

[38] A. M. Wen, S. Shukla, P. Saxena et al., "Interior engineering of a viral nanoparticle and its tumor homing properties," Biomacromolecules, vol. 13, no. 12, pp. 3990-4001, 2012.

[39] A. Niehl, F. Appaix, S. Boscá et al., "Fluorescent Tobacco mosaic virus-derived bio-nanoparticles for intravital two-photon imaging," Frontiers in Plant Science, vol. 6, article 1244, 2016.

[40] S. Shukla, A. L. Ablack, A. M. Wen, K. L. Lee, J. D. Lewis, and N. F. Steinmetz, "Increased tumor homing and tissue penetration of the filamentous plant viral nanoparticle potato virus X," Molecular Pharmaceutics, vol. 10, no. 1, pp. 33-42, 2013.

[41] S. Shukla, A. M. Wen, N. R. Ayat et al., "Biodistribution and clearance of a filamentous plant virus in healthy and tumorbearing mice," Nanomedicine, vol. 9, no. 2, pp. 221-235, 2014.

[42] S. Shukla, R. D. Dorand, J. T. Myers et al., "Multiple administrations of viral nanoparticles alter in vivo behavior-insights from intravital microscopy," ACS Biomaterials Science and Engineering, vol. 2, no. 5, pp. 829-837, 2016.

[43] S. S. Cruz, S. Chapman, A. G. Roberts, I. M. Roberts, D. A. M. Prior, and K. J. Oparka, "Assembly and movement of a plant virus carrying a green fluorescent protein overcoat," Proceedings of the National Acadamy of Sciences of the United States of America, vol. 93, no. 13, pp. 6286-6290, 1996.

[44] M. L. L. Donnelly, L. E. Hughes, G. Luke et al., "The 'cleavage' activities of foot-and-mouth disease virus $2 \mathrm{~A}$ site-directed mutants and naturally occurring '2A-like' sequences,' Journal of General Virology, vol. 82, part 5, pp. 1027-1041, 2001.

[45] M. L. L. Donnelly, G. Luke, A. Mehrotra et al., "Analysis of the aphthovirus $2 \mathrm{~A} / 2 \mathrm{~B}$ polyprotein 'cleavage' mechanism indicates not a proteolytic reaction, but a novel translational effect: a putative ribosomal 'skip,' Journal of General Virology, vol. 82, part 5, pp. 1013-1025, 2001. 
[46] C. Betti, C. Lico, D. Maffi et al., "Potato virus X movement in Nicotiana benthamiana: new details revealed by chimeric coat protein variants," Molecular Plant Pathology, vol. 13, no. 2, pp. 198-203, 2012.

[47] C. Lico, F. Capuano, G. Renzone et al., "Peptide display on Potato virus X: molecular features of the coat protein-fused peptide affecting cell-to-cell and phloem movement of chimeric virus particles," Journal of General Virology, vol. 87, part 10, pp. 3103-3112, 2006.

[48] K. Uhde-Holzem, R. Fischer, and U. Commandeur, "Genetic stability of recombinant potato virus $\mathrm{X}$ virus vectors presenting foreign epitopes," Archives of Virology, vol. 152, no. 4, pp. 805811, 2007.

[49] T. Drepper, T. Eggert, F. Circolone et al., "Reporter proteins for in vivo fluorescence without oxygen," Nature Biotechnology, vol. 25, no. 4, pp. 443-445, 2007.

[50] J. A. Gawthorne, L. E. Reddick, S. N. Akpunarlieva et al., "Express your LOV: An engineered flavoprotein as a reporter for protein expression and purification," PLOS ONE, vol. 7, no. 12, Article ID e52962, 2012.

[51] N. C. Shaner, G. H. Patterson, and M. W. Davidson, "Advances in fluorescent protein technology," Journal of Cell Science, vol. 120, part 24, pp. 4247-4260, 2007.

[52] J. M. Christie, K. Hitomi, A. S. Arvai et al., "Structural tuning of the fluorescent protein iLOV for improved photostability," The Journal of Biological Chemistry, vol. 287, no. 26, pp. 2229522304, 2012.

[53] A. Mukherjee, J. Walker, K. B. Weyant, and C. M. Schroeder, "Characterization of flavin-based fluorescent proteins: an emerging class of fluorescent reporters," PLoS ONE, vol. 8, no. 5, Article ID e64753, 2013.

[54] M. G. Khrenova, A. V. Nemukhin, and T. Domratcheva, "Theoretical characterization of the flavin-based fluorescent protein iLOV and its Q489K mutant," The Journal of Physical Chemistry $B$, vol. 119, no. 16, pp. 5176-5183, 2015.

[55] S. Chapman, C. Faulkner, E. Kaiserli et al., "The photoreversible fluorescent protein iLOV outperforms GFP as a reporter of plant virus infection," Proceedings of the National Acadamy of Sciences of the United States of America, vol. 105, no. 50, pp. 20038-20043, 2008.

[56] A. Cheuk and M. Houde, "A rapid and efficient method for uniform gene expression using the barley stripe mosaic virus," Plant Methods, vol. 13, article 24, 2017.

[57] J. Röder, R. Fischer, and U. Commandeur, "Adoption of the 2A ribosomal skip principle to tobacco mosaic virus for peptide display," Frontiers in Plant Science, vol. 8, article 1125, 2017.

[58] U. K. Laemmli, "Cleavage of structural proteins during the assembly of the head of bacteriophage T4," Nature, vol. 227, no. 5259, pp. 680-685, 1970.

[59] S. Chapman, G. Hills, J. Watts, and D. Baulcombe, "Mutational analysis of the coat protein gene of potato virus X: effects on virion morphology and viral pathogenicity," Virology, vol. 191, no. 1, pp. 223-230, 1992.

[60] J. Tilsner, O. Linnik, M. Louveaux, I. M. Roberts, S. N. Chapman, and K. J. Oparka, "Replication and trafficking of a plant virus are coupled at the entrances of plasmodesmata," The Journal of Cell Biology, vol. 201, no. 7, pp. 981-995, 2013.

[61] S. Santa Cruz, A. G. Roberts, D. A. M. Prior, S. Chapman, and K. J. Oparka, "Cell-to-cell and phloem-mediated transport of potato virus X: The role of virions," The Plant Cell, vol. 10, no. 4, pp. 495-510, 1998.

[62] O. Linnik, J. Liesche, J. Tilsner, and K. J. Oparka, "Unraveling the structure of viral replication complexes at super-resolution," Frontiers in Plant Science, vol. 4, article 6, 2013.

[63] J. Tilsner, O. Linnik, K. M. Wright et al., "The TGB1 movement protein of potato virus $\mathrm{X}$ reorganizes actin and endomembranes into the X-body, a viral replication factory," Plant Physiology, vol. 158, no. 3, pp. 1359-1370, 2012.

[64] M. Bendahmane, M. Koo, E. Karrer, and R. N. Beachy, "Display of epitopes on the surface of tobacco mosaic virus: Impact of charge and isoelectric point of the epitope on virus-host interactions," Journal of Molecular Biology, vol. 290, no. 1, pp. 9-20, 1999.

[65] C. Porta, V. E. Spall, K. C. Findlay, R. C. Gergerich, C. E. Farrance, and G. P. Lomonossoff, "Cowpea mosaic virus-based chimaeras: Effects of inserted peptides on the phenotype, host range, and transmissibility of the modified viruses," Virology, vol. 310, no. 1, pp. 50-63, 2003.

[66] X. Shu, V. Lev-Ram, T. J. Deerinck et al., "A genetically encoded tag for correlated light and electron microscopy of intact cells, tissues, and organisms," PLoS Biology, vol. 9, no. 4, Article ID e1001041, 2011.

[67] M. R. Fernández-Fernández, J. L. Martínez-Torrecuadrada, J. I. Casal, and J. A. García, "Development of an antigen presentation sytem based on plum pox potyvirus," FEBS Letters, vol. 427, no. 2, pp. 229-235, 1998.

[68] C. Porta, V. E. Spall, J. Loveland, J. E. Johnson, P. J. Barker, and G. P. Lomonossoff, "Development of Cowpea Mosaic Virus as a High-Yielding System for the Presentation of Foreign Peptides," Virology, vol. 202, no. 2, pp. 949-955, 1994.

[69] S. Werner, S. Marillonnet, G. Hause, V. Klimyuk, and Y. Gleba, "Immunoabsorbent nanoparticles based on a tobamovirus displaying protein A," Proceedings of the National Acadamy of Sciences of the United States of America, vol. 103, no. 47, pp. 17678-17683, 2006.

[70] G. A. Luke, H. Escuin, P. D. Felipe, and M. D. Ryan, "2A to the fore-research, technology and applications," Biotechnology \& Genetic Engineering Reviews, vol. 26, no. 1, pp. 223-260, 2009.

[71] E. Minskaia, J. Nicholson, and M. D. Ryan, "Optimisation of the foot-and-mouth disease virus $2 \mathrm{~A}$ co-expression system for biomedical applications," BMC Biotechnology, vol. 13, article 67, 2013.

[72] R. L. S. Forster, D. L. Beck, P. J. Guilford, D. M. Voot, C. J. Van Dolleweerd, and M. T. Andersen, "Thecoat protein of white clover mosaic potexvirus has a role in facilitating cell-to-cell transport in plants," Virology, vol. 191, no. 1, pp. 480-484, 1992.

[73] O. N. Fedorkin, A. G. Solovyev, N. E. Yelina et al., "Cell-to-cell movement of potato virus $\mathrm{X}$ involves distinct functions of the coat protein," Journal of General Virology, vol. 82, part 2, pp. 449-458, 2001.

[74] O. N. Fedorkin, A. Merits, J. Lucchesi et al., "Complementation of the movement-deficient mutations in potato virus $\mathrm{X}$ : Potyvirus coat protein mediates cell-to-cell trafficking of Cterminal truncation but not deletion mutant of potexvirus coat protein," Virology, vol. 270, no. 1, pp. 31-42, 2000.

[75] K. J. Oparka, A. G. Roberts, I. M. Roberts, D. A. M. Prior, and S. S. Cruz, "Viral coat protein is targeted to, but does not gate, plasmodesmata during cell-to-cell movement of potato virus X," The Plant Journal, vol. 10, no. 5, pp. 805-813, 1996. 
[76] J. M. Christie, "Phototropin blue-light receptors," Annual Review of Plant Biology, vol. 58, pp. 21-45, 2007.

[77] X. Dang, S. Chalkias, and I. J. Koralnik, "JC virus-iLOV fluorescent strains enable the detection of early and late viral protein expression," Journal of Virological Methods, vol. 223, pp. 25-29, 2015. 


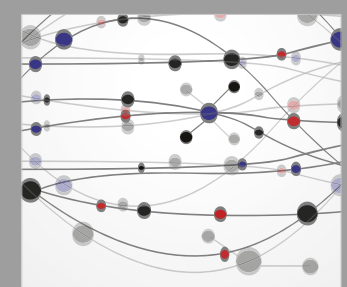

The Scientific World Journal
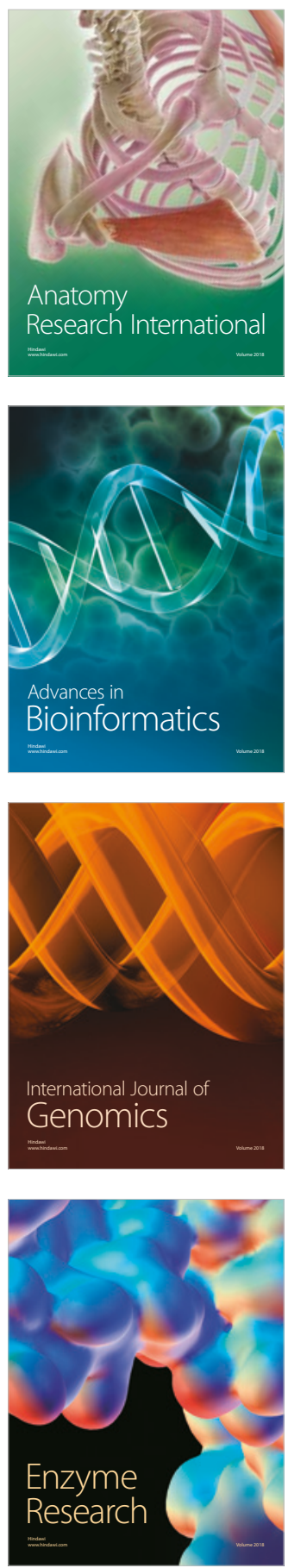
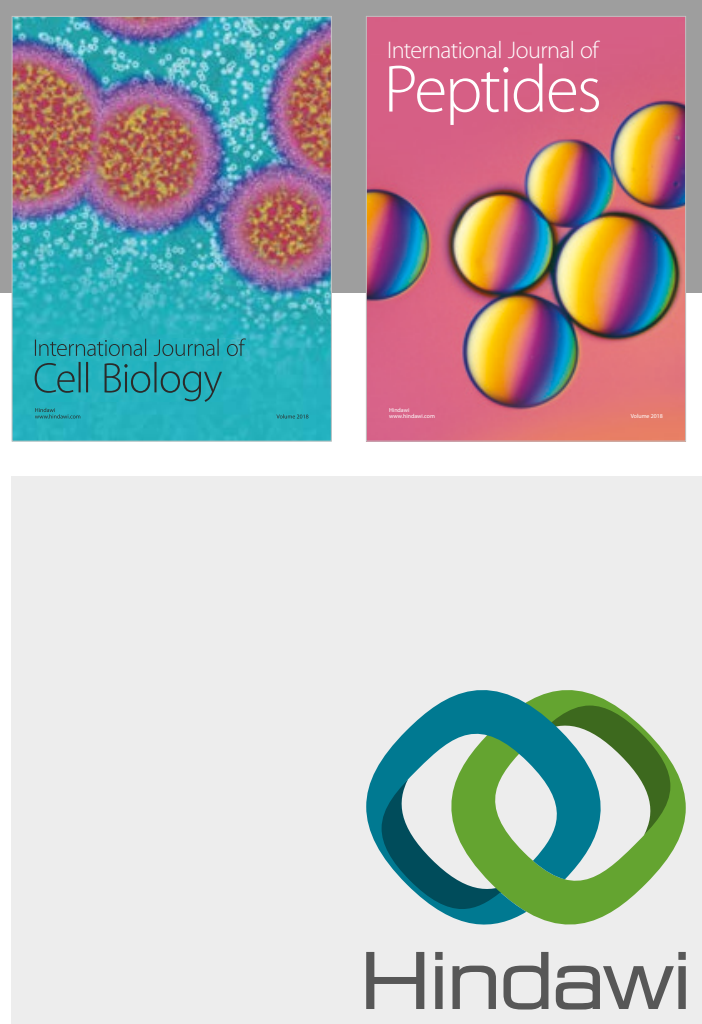

Submit your manuscripts at

www.hindawi.com
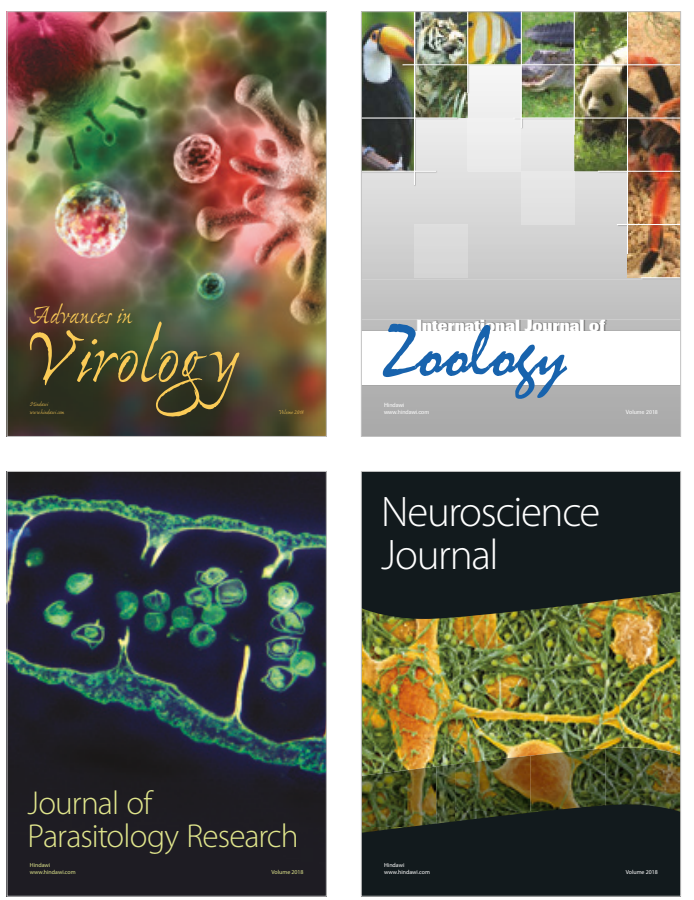
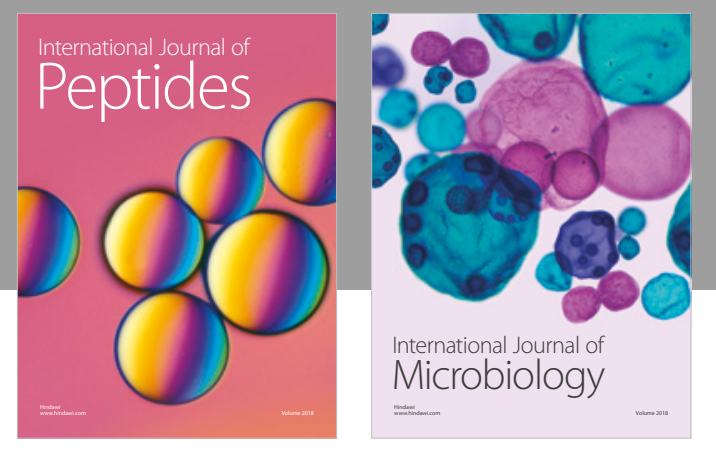

nternational Journal of Microbiology
Journal of
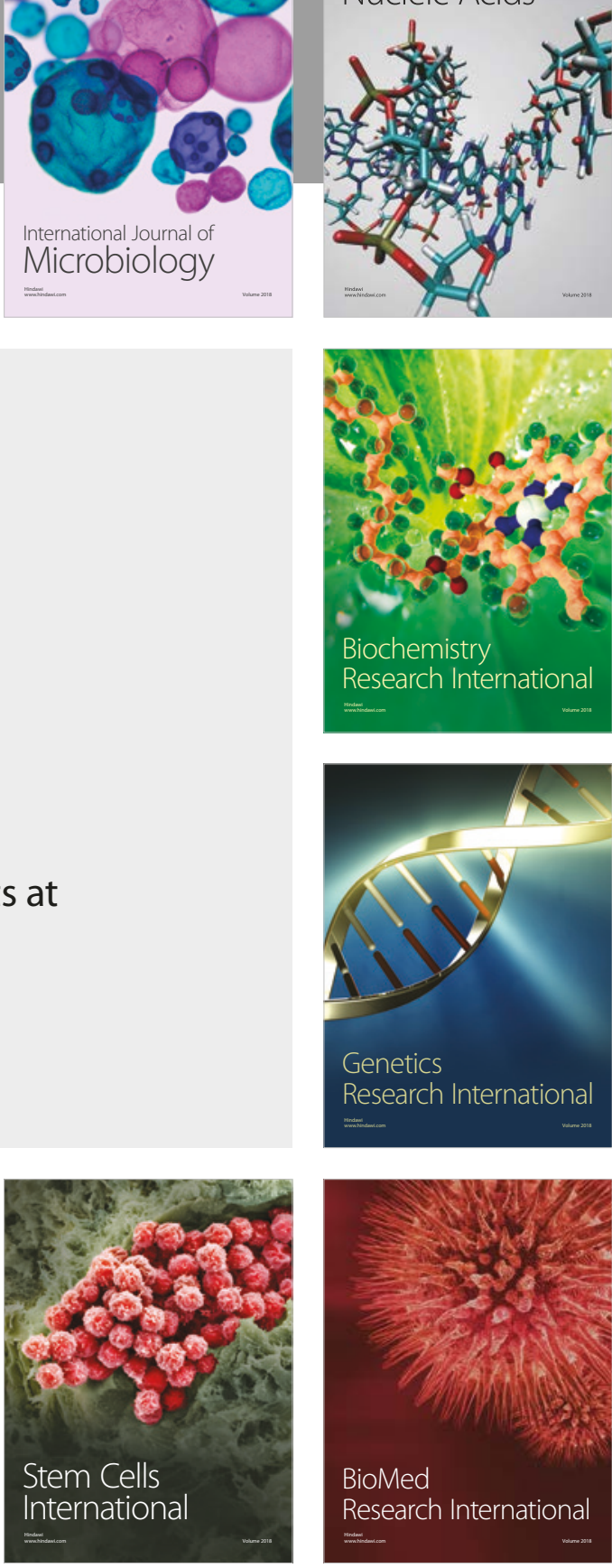
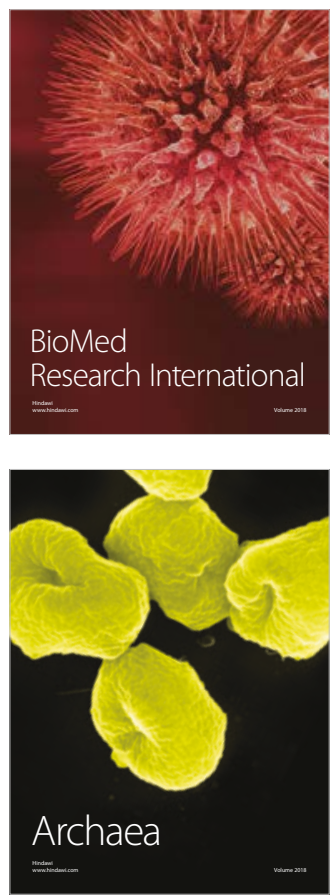